\title{
The Situation and Development Strategies for Environmental Protection Standardization in Transportation Industry of China
}

\author{
Huan Liu ${ }^{1 *}$, Yanqin Wang ${ }^{1}$ and Shegang Shao ${ }^{1}$ \\ ${ }^{1}$ Research Institute of Highway Ministry of Transport, Beijing 100088, China
}

\begin{abstract}
Standardization for environmental protection in the transportation industry is an important driving force for the development of green transportation. This study introduces the current status and main problems of environmental protection standardization in transportation. In addition, major countermeasures, such as strengthening the system construction and basic support, are studied and proposed to provide theoretical support and research basis for future standardization in related areas.
\end{abstract}

\section{Introduction}

As China's economic development enters a new normal, transportation as a basic, pioneering and service industry, has shown novel characteristics. As one of the main development factors, ecological environment resource is further strengthened through rigid constraints. Thus, the sustainable development of transportation is under severe challenges. To solve the increasingly prominent resource and environmental problems caused by the industry development, integration of ecological civilization construction in the entire process of transportation development is necessary. This integration can accelerate the establishment of a resource-saving and environmentfriendly transportation industry, and realize green, cyclic, and low-carbon development of transportation in China.

A green, cyclic, and low-carbon transportation system can effectively promote the sustainable and healthy development of the transportation economy and overall social progress. In the construction of such transportation system, standardization exerts a fundamental and strategic role. Therefore, the active study of environmental protection standardization in transportation is imperative and better leverages its role in the promotion of environmental protection, energy conservation, and emission reduction in the country. Through standardization, the transportation industry could achieve green development.

\section{Standardization situation}

\subsection{Development status}

\subsubsection{Overseas status}

At present, no specialized agencies in developed countries such as the United States and Japan are specifically responsible for the construction of standardization systems and the revision of standards in the field of transportation, environmental protection, and energy conservation. Rather, standardization organizations in different fields are mainly responsible for transportation development in the United States, such as the American Public Transportation Association (APTA), Institute of Transportation Engineers (ITE), American Society of Automotive Engineers, American National Standards Institute, and the National Association of Highway and Traffic Administrators ${ }^{[1]}$. Among them, the climate change team under APTA is responsible for planning and measuring the impacts of climate change and greenhouse gas emissions $^{[2]}$, including efforts in the standardization of environmental protection in transportation. The European Standardization Committee is mainly responsible for the European transport environment system. Emissions and noise directives for mobile sources (vehicles) are specially formulated while considering the atmospheric and noise pollution in its environmental standardization system ${ }^{[3]}$. Japan's transportation-related standards are divided into fields, such as automobiles, railways, navigation, aviation, logistics, and harbors. These standards are separately supervised by the Japan Industrial Standards Committee (JISC), Japan Standards Association, and the Japan Automobile Research Institute, under the overall guidance of the Ministry of Land, Infrastructure, Transport and Tourism and the Railway Technical Research Institute. Among them, JISC coordinates 27 technical specialized committees, such as for the environment, resource recycling, transportation, and logistics. JISC formulates standardization strategies and guides the standardization and revision work according to the needs of various fields ${ }^{[4]}$. The Automobile Sub-Committee specifically proposes solutions to hot issues of national and international environmental standards on resources.

The above discussion shows that compared with those of China, the standardization works of foreign transportation industries are meticulous with different

\footnotetext{
"Corresponding author's e-mail: 64887415@qq.com
} 
responsible agencies, more complete content, higher quality, and certain technical authority.

\subsubsection{Current situation in China}

Standardization of environmental protection in transportation in China started in the early 1990s, relatively later than other countries such as U.S. and Japan. At that time, in response to the national standardization work deployment, the Ministry of Transport established the "Technical Committee for Environmental Protection Standardization of Ministry of Transport". This set up was based on the "Environmental Protection Professional Committee of Standardization" and "Metrology Committee of the Ministry of Transport", which are responsible for environmental protection standardization in transportation. In the beginning of its establishment, the environmental protection committee played an important role in standardizations in highway and water transportation. The committee likewise organized several environmental protection standards, which formed effective support for the supervision and management of China's transportation industry.

In recent years, the country's requirements for the development of green transportation and establishment of transportation energy-saving and emission-reduction standards have gradually increased. Continuous support for the construction of green transportation system requires standardization of the industry's environmental protection, energy conservation, and emission reduction works. In addition, the development of green and lowcarbon circular transportation can be explored on the basis of the National Standardization System Construction Development Plan (2016-2020) (No. 89 [2015] of the General Office of the State Council) ${ }^{[5]}$, 13th Five-Year Plan for Transport Standardization (No. 15 [2016] of the Transportation Science and Technology), Green Transportation Standard System (2016) (No. 191 [2016] of Transportation Science and Technology), Water Pollution Prevention Action Plan ${ }^{[6]}$, Air Pollution Prevention Action Plan [7], 13th Five-Year Plan for Development of Energy Saving and Environmental Protection for Transportation ${ }^{[8]}$, Opinions on Strengthening Energy Conservation Standardization, Guiding Opinions on Accelerating the Development of Green Cycle and Low Carbon Transportation, Principles and Requirements for the Preparation of Standard System
Tables, and other documents. The current standardization of transportation environment protection system is reclassified according to elements specific to the technical and management requirements for environmental protection of highway and water transportation according to the principles of coordination, advances, systematicness, and guidance, which breaks down the current model based on the original standards of transportation $^{[9]}$.

\subsection{Standard system coverage}

Environmental protection standardization in transportation is fully developed considering the industry characteristics and avoiding intersection with the content of standardization in other fields. Excluding engineering construction standards of transportation infrastructure, the system mainly summarizes basic general technical requirements, service management, and monitoring and evaluation standards related to ecological protection, pollution prevention, energy conservation and carbon reduction, environmental safety, and emergency response to pollution accidents.

Only national and industry standards are included in the system, whereas local and enterprise standards are excluded.

\subsection{Standard system structure levels}

The existing system structure for environmental protection standardization in transportation mainly includes six categories: (a) basic standards, which comprises two parts that are mainly aimed at unified and common standards; (b) energy conservation and carbon reduction standards, which consists of two parts; (c) ecological protection standards, which contains three parts; (d) pollution prevention standards, which consists of five parts; (e) resource recycling standards, which comprises two parts; and (f) supervision (inspection) measurement, statistics, assessment, and supervision standards, which contains four parts. In addition, relevant and current national standards are included, covering four parts according to statistics on environmental quality, namely, ecological protection, pollutant emissions, energy conservation, and carbon reduction. Figure 1 shows the structure of the standard system for transportation environmental protection. 


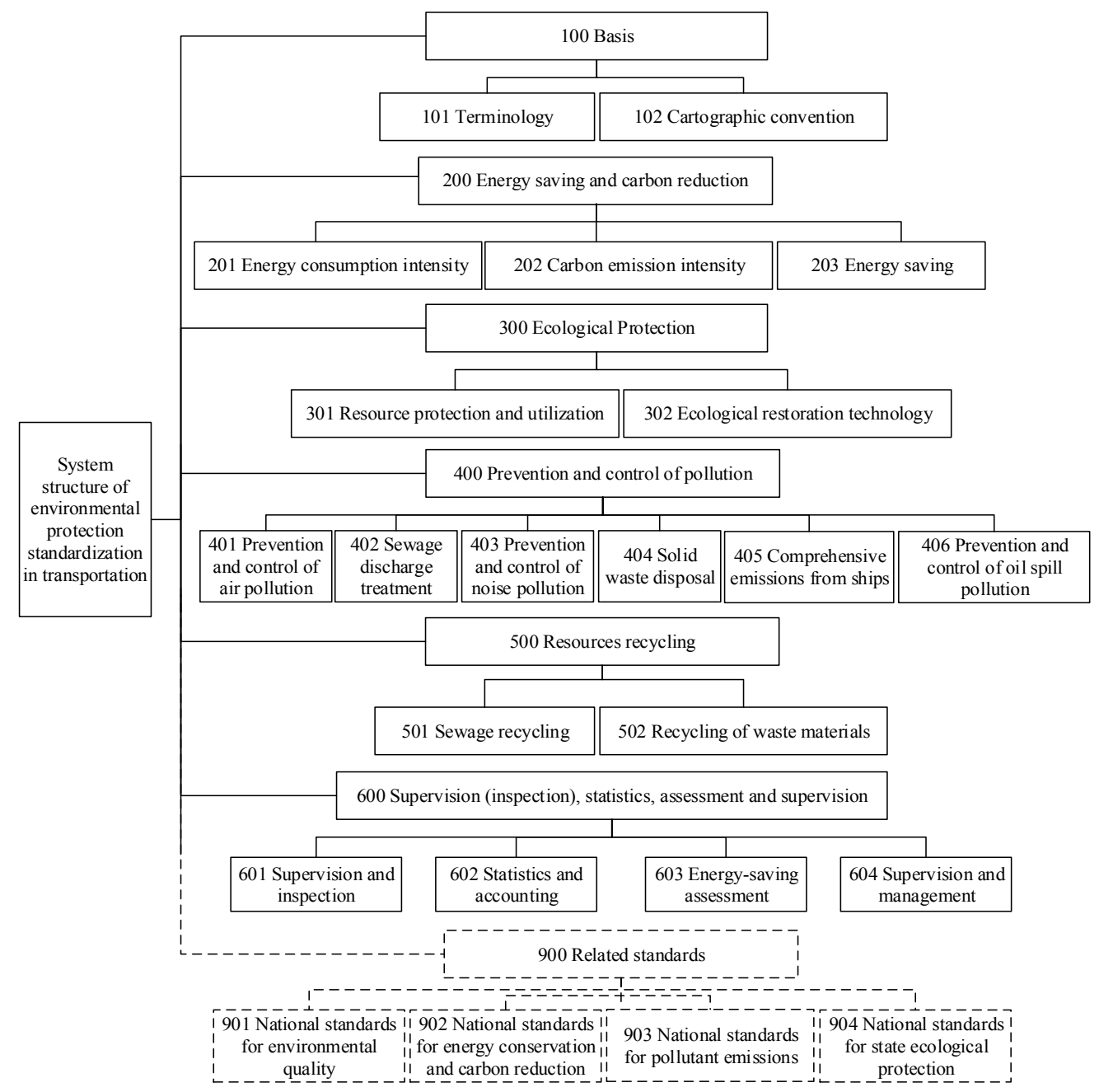

Figure 1. System structure of environmental protection standardization in transportation

\subsection{Descriptions of each category and their standard content}

\subsubsection{Basis standard}

Basis standards mainly include terminology standards in the fields of energy conservation and environmental protection in highway and water transportation.

\subsubsection{Energy saving and carbon reduction standard}

Energy saving and carbon reduction standards mainly include carbon dioxide emissions intensity and limit standards for transportation facilities, as well as standards for energy-saving design of highway and water transportation projects, etc.

\subsubsection{Ecological protection standard}

Ecological protection standards mainly include technical standards for the protection and utilization of plants, water, topsoil, and other resources during the construction period, as well as for ecological restoration.

\subsubsection{Prevention and control of pollution standard}

Prevention and control of pollution standards mainly include technical standards and product standards for noise pollution prevention and control during the construction and operation of highway and water transportation projects, related treatment device standards, and collection methods for sewage and production wastewater from highway and water transportation engineering facilities, etc.

\subsubsection{Resources recycling standard}

Resources recycling standards mainly include technical standards for wastewater treatment and recycling, as well as the processing and recycling of waste materials.

\subsubsection{Supervision (inspection), statistics, assessment and supervision standard}

Supervision (inspection), statistics, assessment and supervision standards mainly include standards for environmental monitoring technology and energy consumption detection methods, standards for environmental protection statistics, standards for 
evaluation of green transportation facilities, environmental impact assessment of transportation construction and operation, and supervision and management of energy conservation and carbon reduction, etc.

\subsection{Statistics of existing standards}

Environmental protection in transportation has 46 related standards, which currently includes 6 national standards,
32 industry standards, each 4 planning plans for national and industry standard development, all of which are recommended standards. Among these standards are 4 for basic operations, 4 for energy conservation and carbon reduction, 3 for ecological protection, 13 for pollution prevention, 3 for resources recycling, and 12 for supervision (inspection) measurement, statistics, and assessment. Table 1 presents the statistics of the existing standards.

Table 1. Statistics of existing standards of environmental protection in transportation

\begin{tabular}{lcccc}
\hline & \multicolumn{2}{c}{ Published projects } & \multicolumn{2}{c}{ Planning projects } \\
\cline { 2 - 5 } \multicolumn{1}{c}{ Classification } & $\begin{array}{c}\text { National } \\
\text { standard }\end{array}$ & $\begin{array}{c}\text { Industry } \\
\text { standard }\end{array}$ & $\begin{array}{c}\text { National } \\
\text { standard }\end{array}$ & $\begin{array}{c}\text { Industry } \\
\text { standard }\end{array}$ \\
\hline Basic standards & 1 & 3 & 0 & 0 \\
Energy-saving and carbon reduction standards & 1 & 3 & 0 & 0 \\
Ecological protection standards & 0 & 3 & 0 & 0 \\
Prevention and control of pollution standards & 0 & 13 & 0 & 1 \\
Resources recycling standards & 0 & 3 & 0 & 0 \\
Supervision (inspection), statistics, assessment and & 4 & 7 & 4 & 3 \\
supervision standards & $\mathbf{6}$ & $\mathbf{3 2}$ & $\mathbf{4}$ & $\mathbf{4}$ \\
Total & & & & \\
\hline
\end{tabular}

\section{Existing problems}

\subsection{Uneven standard distribution and remarkable differences in the number of standards in several categories}

Problems occur in the current relevant standards, such as the quite different number of items in each category, uneven distribution, and several missing standards. These problems are as follows. (a) In the energy-saving and carbon-reduction categories, all standards are currently published and no new project approval standards have been established. (b) In the category of ecological protection, in terms of "ecological restoration technology", the standards of "vegetation restoration materials for highways and roads" serve as the main body. No project plan is established for ecological restoration of water transportation and other directions, or the standards of highway water transportation in the "resource protection and utilization" direction. (c) The current standards for pollution prevention and control categories account for a large proportion in the system, but they currently concentrate on sewage recycling and noise in highway service areas. Standards of sewage treatment in air pollution prevention and water transportation should be strengthened.

\subsection{Insufficient training in standards promotion and unsuccessful implementation}

The target users of environmental protection standardization in transportation mainly include the following: provincial, municipal, and autonomous regional authorities; design, construction, and operation management units in highway, water transportation, and other fields; transportation research institutions and colleges; and related enterprises. Based on the evaluation of the implementation effect of the standards issued more than one year in recent years, several users failed to obtain the relevant release information in time and to grasp its main content due to limited promotion and implementation, hence the implementation effect of the standard may not meet the expected goals.

\section{Development countermeasures}

The use of sections to divide the text of the paper is optional and left as a decision for the author. Where the author wishes to divide the paper into sections the formatting shown in Table 2 should be used.

\subsection{Strengthen the construction of the standard system and supplement the blank areas}

Environmental protection standardization in transportation is formulated by absorbing the comprehensive standards system of transportation and related mature standards in other professional fields of the industry. These standards are specific to characteristics of transportation environmental protection, energy conservation, emission reduction, and future standard preparation. To promote the development of green transportation and adapt to requirements of pollution prevention and construction of a strong transportation, further optimization of existing standard structures is necessary. In addition, continuous updates and improvements can be achieved energy conservation and carbon reduction, ecological protection, and resources recycling by combining the key points of national standardization work to provide a basis for the transportation standardization in the 14th Five-Year Plan. 
Based on the existing system structure, the remodeling research on the standard system structure for 2035 and the vital forward-looking technical standards can be organized and performed by adhering to the national and industry key tasks as guidance. A safe, convenient, efficient, green, economical, modern, and integrated system structure for environmental protection in transportation is discussed and constructed to accelerate the standardization of green and intelligent new technologies in the transportation industry.

\subsection{Strengthen basic support of standardization and service capacity construction}

Improved training and implementation of standards is imperative. Training on the promotion of newly-released standards in key areas can be organized to expand the impact, increase industry awareness, and promote the implementation of standards. A standard implementation information feedback system can be used to establish implementation of excellent project evaluation. Relying on major engineering construction projects, pilot demonstrations that mainly promote the application of standard engineering are developed, and related management systems for the effective application of industry standards in project design, bidding, construction, and delivery acceptance are explored. The ability and level of workers in standardizing and revising the systems in the field of transportation and environmental protection should be increased to improve the quality of content and preparation of the description, which can lay the foundation for the standardization's successful progress.

\section{Conclusion}

Despite its early beginnings, environmental protection standardization in transportation initially showed gradual development. At present, a gap remains between the current structure compared with other mature standards systems. However, the country's prior support and attention to environmental protection and energy conservation, together with the rapid development of science and technology in professional fields, definitely promotes the economic and social development of the transportation industry and the construction of an ecological civilization. Adhering to studies of the standardization system, progressively formulating new standards or revising the original ones, and abolishing obsolete or soon-to-be-expired standards are recommended.

\section{References}

1. Song B. (2015) Enlightenment of Foreign Building Energy Standardization System to China. Standardization of Engineering Construction, 9: 2022.

2. Wu Y., Liu T. (2014) Experience and its Enlightenment of American Public Transport
Standardization. Communications Standardization, 42(21): 52-55.

3. $\mathrm{Hu}$ B. (2005) European Union Environmental Standard System and its Analysis. Environmental Protection of Chemical Industry, 25(3): 195-198.

4. Standardization strategy (introduction). (2002) Japanese Industrial, Standards Committee.

5. The National Standardization System Construction Development Plan (2016-2020). (2015) General Office of the State Council.

6. Water Pollution Prevention Action Plan. (2015) General Office of the State Council.

7. Air Pollution Prevention Action Plan. (2013) General Office of the State Council.

8. 13th Five-Year Plan for Development of Energy Saving and Environmental Protection for Transportation. (2016). Ministry of Transport.

9. Liu H., Li J., Shao S. (2017) The Thinking and Structure of the Environmental Protection and Energy-saving Standard System in the Transportation Industry, 39(2): 31-34. 